International Journal of Database Management Systems (IJDMS ) Vol.10, No.5, October 2018

\title{
AfFinity Clusters for Business Process INTELLIGENCE
}

\author{
Rajeev Kaula \\ Department of Management and Information Technology, College of Business, Missouri \\ State University, Springfield, MO, USA
}

\begin{abstract}
Business process intelligence improves operational efficiency that is essential for achieving business objectives, besides facilitating competitive advantage. As an organization is a collection of business processes, enhancing business process performance on a continual basis is essential for organizational success. This paper outlines the concept of affinity clusters that can influence process performance with respect to some success criteria. Affinity refers to the percentage of time certain dimensional factors occur together with respect to some success measure. The paper illustrates the concepts through an adaptation of Oracle E-Business Suite Lead to Forecast business process that is implemented in Oracle's PL/SQL language.
\end{abstract}

\section{KEYWORDS}

Business Intelligence, Process Intelligence, Business Process, Oracle, PL/SQL

\section{INTRODUCTION}

Business process intelligence is an application of business intelligence (BI) concepts for business operations. Although the role of $\mathrm{BI}$ in discovering emerging opportunities for competitive advantage has gained a lot of attention [10, 11, 12, 23, 28, 29, 33, 39], the utilization of its concepts toward business process intelligence is evolving [15, 16, 18, 25, 26, 32]. As organizations are a collection of business processes, insights on improving operational efficiency and identifying bottlenecks is essential to achieve business objectives, besides facilitating competitive advantage.

The traditional approach in business intelligence is to first model data in a data warehouse in the form of multi-dimensional models through an analysis of business operations involving business activities or business processes [6,31]. Thereafter, BI generates insights through analytics on the multi-dimensional model in the form of star schema or its variants [1, 21, 22, 24, 34, 40]. Such analytics provide information on what combination of dimension factors are associated with various measure values or its aggregations. Even though analytics on star schema is important as it allows an organization to make sense of data with respect to business process operations, such analytics are essentially a snapshot on some aspect of the business process operations.

This paper proposes an extension of traditional business intelligence analytics by outlining affinity among dimensional factors as a way to improve insights on business process performance. For example, consider a store checkout business process. Suppose the key measure that determines the success of the checkout business process is checkout duration. The traditional BI analytics associated with checkout star schema will show for instance the dimensional factors like time of the day, number of customers and payment types, and product types and promotions, associated with specific checkout duration. Additional analytics may even show what dimensional factors are making the checkout duration quick, slow, or even bordering on average. In a way, the traditional BI is providing a good snapshot of store checkout performance. 
However, this traditional store checkout business process analytics can be extended to include insights on whether certain groups or combination of dimensional factors are contributing more toward improvement or decline in business process performance with respect to some success measure. This grouping of dimensional factors is based on whether there is some affinity among them with respect to performance success measure. Affinity refers to the percentage of time certain dimensional factors occur together with respect to some success measure. So using the previous checkout example it would suggest what combination of products, promotions, customer types, payment types, and times of day occur together say $50 \%$ or $60 \%$, or any other higher percentage of time with respect to various checkout duration measures. This insight on combination of dimension factors that can impact business performance is referred in the paper as affinity clusters analytics.

Compared to traditional analytics, affinity clusters analytics provides a more fine-tuned insight on business process performance. Incorporation of affinity clusters enables (i) the viewing of the levels of affinities that may exist among dimensional factors for various success measures, (ii) allow the business process to focus on the reasons why certain combination of dimensional factors are causing a drag on performance goals due to their affinities, and (iii) enhance support for certain combination of dimensional factors with higher affinity that are enabling the business process to achieve its performance goals. Insight into affinities can also result in the setup of analytic triggers with respect to the monitoring of dimensional factors or development of key performance indicators.

There have been attempts toward analysis of business process operations in the form of process monitoring, process analysis, process discovery, conformance checking, prediction and optimizations [9, 17]. Besides, there have also been utilization of business rules for business process intelligence $[4,13,18,27]$. These approaches either tie business rules to measures that are defined a priori through existing policies without much emphasis on database analysis or outline business rules for specific performance metrics.

A key element in affinity cluster analytics is the identification of relevant dimensional information. As business process activities are flow-oriented, modeling of dimensional information in a way that reconciles with the fluidity in process operations is essential. So, instead of iterative approaches toward such modeling [31], there should be clear mapping of business process activities to dimensional information. An approach to map dimensional information with business process activities is referred in the paper as dimension flow model.

This paper (i) outlines a dimension flow model to identify relevant dimensional information utilized during business process activities, (ii) applies such information to create a star schema for developing affinity clusters that influences business process success measure, and (iii) delineates the application of affinity clusters in the form of analytic triggers and key performance indicators. The paper illustrates the concept through a prototype based on Oracle E-Business Suite Lead to Forecast business process that is implemented with Oracle's PL/SQL language.

The paper is organized in the following way. First the relevant business process intelligence research is reviewed. Next, the dimension flow modeling concepts are outlined along with the lead to forecast dimension model. The methodology to transform affinity cluster star schema into affinity clusters analytics through the Web prototype is outlined thereafter. The paper concludes with an outline of affinity clusters analytics application through analytic triggers and key performance indicators.

\section{RELATED WORK}

Operational intelligence analyzes business processes to ensure that operational workflow is efficient and consistent with their stated objectives. The goal is to optimize such processes for 
successful performance. There have been three approaches towards the utilization of BI concepts for business process based operational analytics. The first approach occurs in three variations in the form of (i) using BI concepts for dynamic process performance evaluation $[6,8,18,35,36]$, (ii) analyze event $\operatorname{logs}$ to improve the quality of business processes $[2,3,14]$, and (iii) monitor process instances to inform users about unusual or undesired situations [17]. These variations are either short on implementation or apply BI analytics to individual business processes for discrete performance assessment associated with business process activities; but, do not emphasize concepts similar to affinity cluster.

The second approach emphasizes analytics on selected business process activities within the modeling process [7]. It shows reference to analytic information during business process modeling as a way to incorporate BI. The approach emphasizes use case scenarios, but is short on implementation details on how to evaluate performance.

The third approach focuses on utilizing BI to reduce redundant specifications of recurrent business functions when modeling business processes [37]. It fosters reuse of business function specifications and helps to improve the quality and comparability of business process models. This approach is focused on the modeling process only.

\section{DIMENSION FLOW MODEL}

Dimension flow model [20] is a graphical conceptual method to identify dimensional (analytic) information that can be considered as relevant for analyzing business process activities. Dimension flow modeling is based on information flow modeling concepts $[18,24]$ and is valuable because it provides a basis for separating information from transactional processing for analytical processing. Development of dimension flow can be beneficial for (i) understanding the nature of analytic information without the complexities of data storage, and (ii) comprehending how business process activities are affected by the such information. Figure 1 shows the generic outline of a dimension flow model.

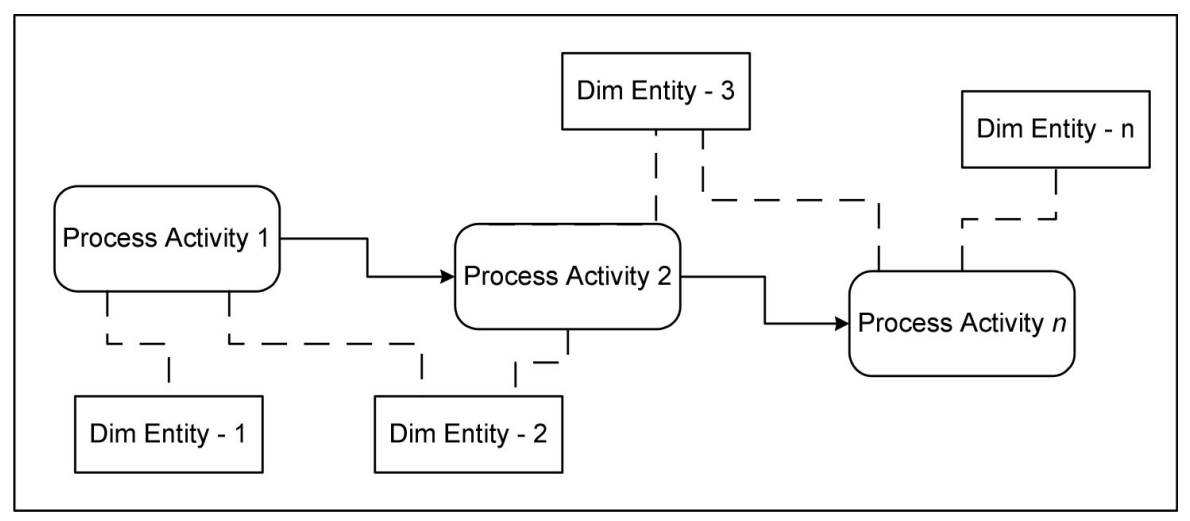

Figure 1. Dimension Flow Model

In Figure 1, the business process model consists of various activities labeled as Process Activity 1, Process Activity 2, and so on. Each process activity's utilization of dimensional information is represented through various dimensional entity types like Dim Entity - 1, Dim Entity - 2, and so on. It is possible that the same dimensional entity type may be utilized by other process activities, like Dim Entity - 2 interacts with Process Activity 1 and Process Activity 2, while Dim Entity - 3 interacts with Process Activity - 2 and Process Activity - n.

The dimensional entity types of the dimension flow model are derived from the transactional entity relationship model (ERD) of the business process. Each dimensional entity type structure 
may include some or all the attributes of the associated transactional entity type that are essential for the purpose of analysis. Unlike a transactional ERD data model the dimensional entity types are standalone entity types which can later be transformed as dimensions in associated multidimensional models.

Figure 2 shows an example of a dimension flow model adapted from Oracle's Order to Pay business process. The diagram is a simplification of a similar business process as outlined by Oracle E-Business Suite (ERP) software. It can be categorized into five stages: (i) configure sales order, (ii) plan and prepare for order shipment, (iii) ship order and logistics, (iv) invoice customer on the order shipment, and (v) process order payment.

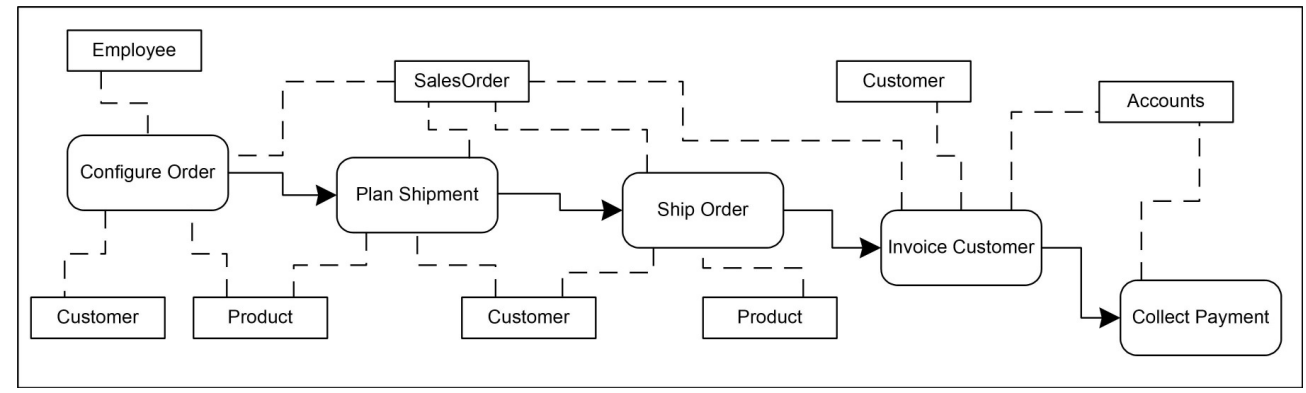

Figure 2. Order to Pay Dimension Flow Model

For the purpose of the prototype later in the paper, we focus on the dimension flow model adapted from Oracle's Lead to Forecast business process as shown in Figure 3. The diagram is a simplification of a similar business process as outlined by Oracle E-Business Suite (ERP) software. It can be categorized into four stages: (i) generate sales lead, (ii) assess lead potential, (iii) convert lead to opportunity, and (iv) opportunity to forecast.

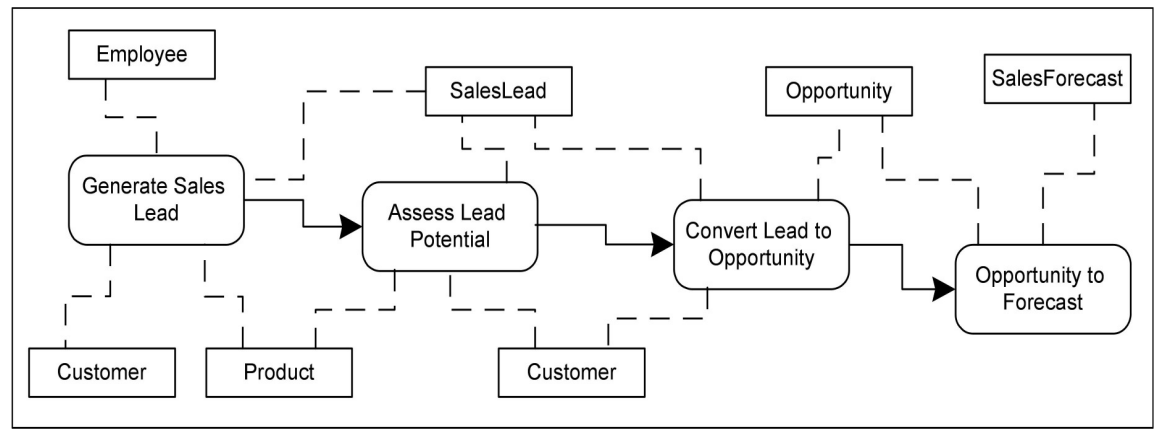

Figure 3. Lead to Forecast Dimension Flow Model

Generate sales lead is the initial activity that commences when a sales representative receives a call from a customer contact requesting the need for further assistance before placing an order. The details about a lead are recorded by the software automating the process and a lead number is generated. Once the tasks associated with the lead have been completed and recorded, the sales representative assesses the lead potential and records the probability of the sale being accomplished. This moves the recorded lead to the next stage in the process where it is transformed into a sales opportunity. As the sales opportunity materializes, the software automating the process provides the ability to further transform the status of the opportunity to a forecast.

At the surface level the dimension flow model may seem similar to data flow models [38]. However, the dimension flow model avoids some of the key tenets of the data flow models like 
decomposition, leveling, and data stores. It is derived from the operational data model wherein (i) the database relationships are ignored, and (ii) entity types and attributes that should be part of analysis are selected. Figure 4 is the operational data model of Lead to Forecast. For instance, in the figure, Inventory is a weak entity type with many attributes. But in the dimension flow model only one of the attributes Product Description is considered. Similar considerations influence the selection of other dimension entity types and their attributes.

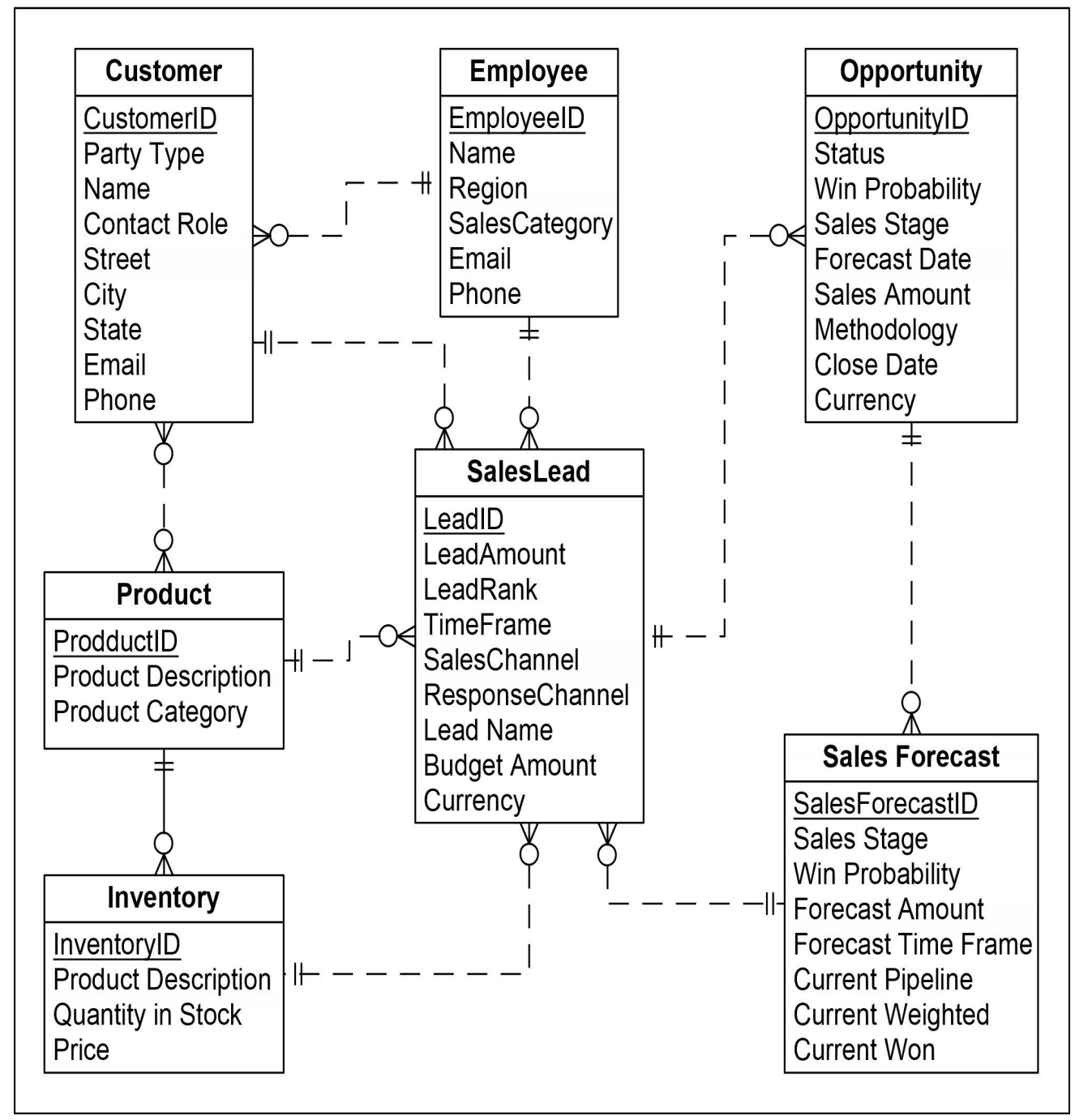

Figure 4. Operational Data Model for Lead to Forecast

The contents of dimensional entity types of Lead to Forecast dimension flow model of Figure 3 are described in Figure 5. 
International Journal of Database Management Systems (IJDMS ) Vol.10, No.5, October 2018

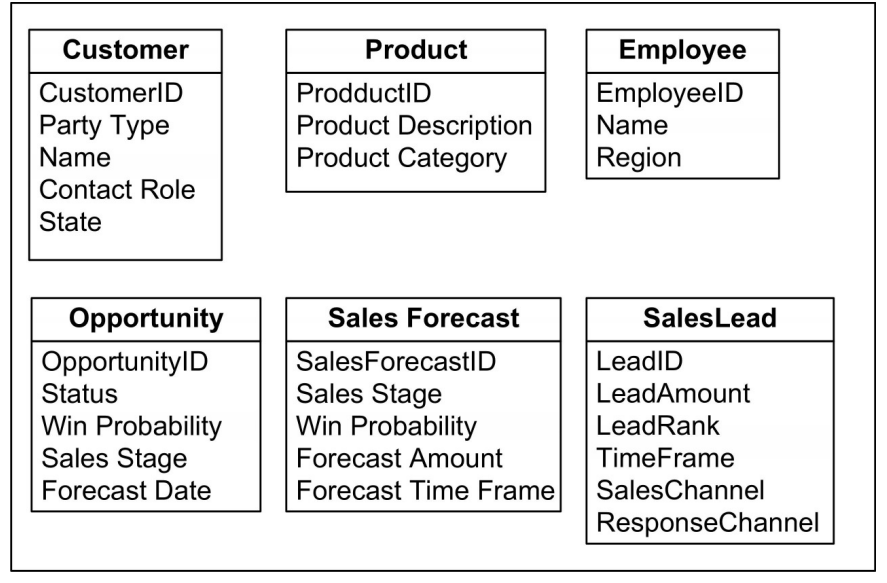

Figure 5. Lead to Forecast Dimension Flow Model Entity Types

The interaction of dimensional entity types in dimension flow model with business process activities enable a more accurate mapping of dimensional attributes with business process activities. Such mapping later facilitates the development of analytic triggers and key performance indicators.

\section{TRANSForm Dimension Flow MODEl into AFFinity CluSTERS}

To perform affinity clusters analytics a prototype is developed wherein the dimension flow model is utilized to develop a star schema. Thereafter the star schema is analyzed to discern the extent to which some or all of the dimensional entity type attributes contribute toward the extended insights offered through affinity clusters. In short, the steps involved in the development of affinity clusters analytics are as follows: (i) create a star schema with some performance measure that is considered key to business process success, (ii) transform the star schema into affinity clusters, and (iii) reference the dimension flow model to set the appropriate analytic triggers and key performance indicators to ensure performance success.

\subsection{Star Schema Through Dimensional Flow Model}

Relevant dimensional entity types attributes from the dimension flow model are identified in the structuring of the star schema. Once the selections has been made it is important to identify an attribute that can serve as a success attribute for business process performance.

Since the purpose of affinity cluster is to provide the impact of clusters of individual information (dimensional attributes) on performance measure, the traditional star schema dimension table structure (Figure 6) is modified as (i) attributes in dimension tables have relationships with other attributes thereby making it difficult to assess individual impact, and (ii) if an attribute in dimension entity type appears in other entity types or business process activities assessing it individually is more insightful. 
International Journal of Database Management Systems (IJDMS ) Vol.10, No.5, October 2018

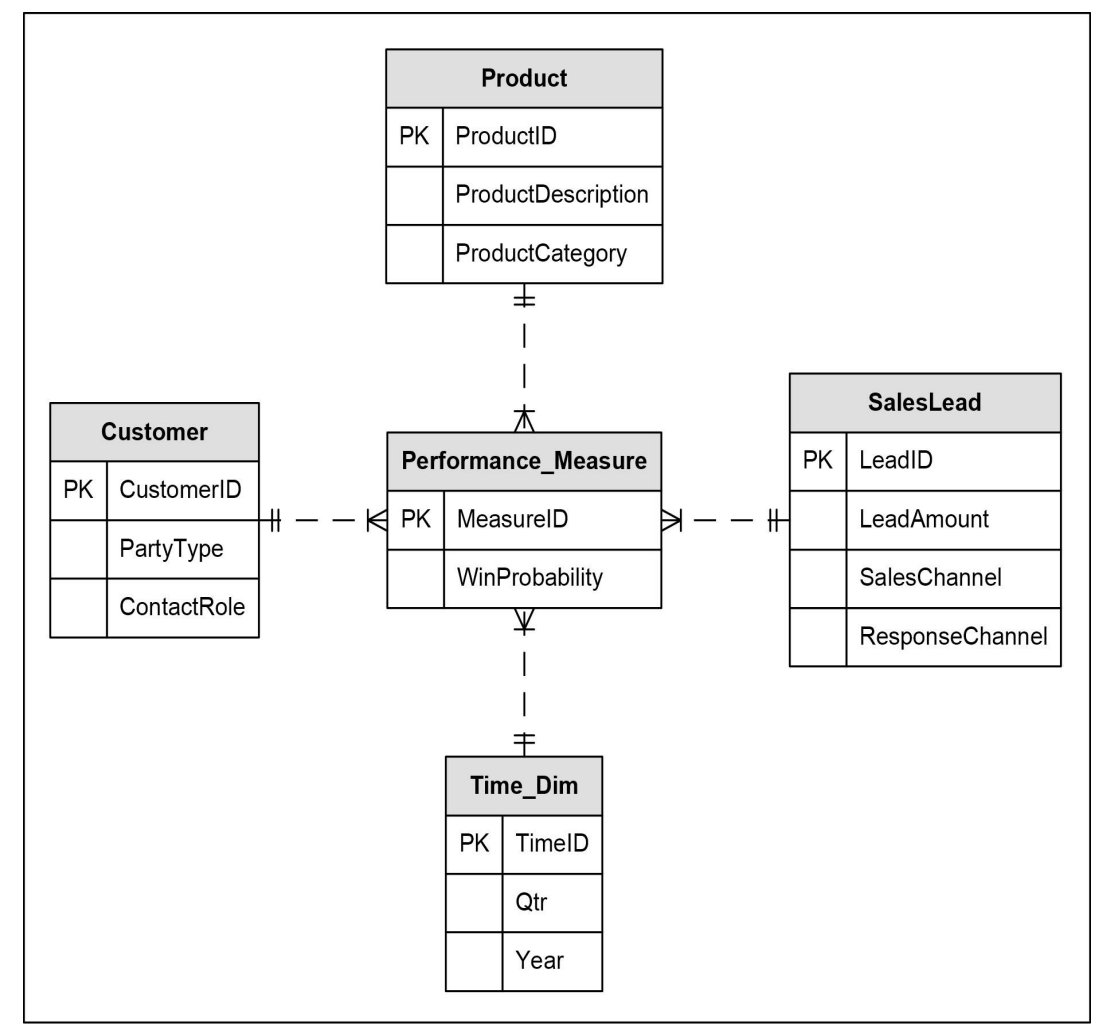

Figure 6. Traditional Star Schema for Lead to Forecast

So, instead of dimension tables having many attributes, the affinity cluster star schema will have dimension tables with single attribute. This ensures better affinity assessment of the attribute within the scope and context of business process success goals.

To illustrate the structuring of the star schema through the dimensional flow model consider the Lead to Forecast information flow model of Figure 3 and the associated dimensional entity types of Figure 5. Suppose one criteria to judge lead to forecast business process performance is to know how sales leads convert into an actual order successfully over time. The dimension attribute that can provide this information is "Win Probability" in the SalesLead dimensional entity type. The higher the Win Probability, the better the chances of turning sales lead into an actual order. The nature of Win Probability value is based on the business's previous interaction with customer, budgeted amount, time frame, and so on. It is up to the business to decide what should be the appropriate attribute to measure business process success.

Figure 7 shows the star schema structure where Win Probability is the fact measure and Customer Type, Customer Contact, Product Category, SalesLead Channel, and SalesLead Response become the dimensions. Since performance assessment can be time based, time dimension is also added to the schema. The dimensions structure is not hierarchical. For the purpose of the prototype only certain attributes are considered for dimensions. 
International Journal of Database Management Systems (IJDMS ) Vol.10, No.5, October 2018

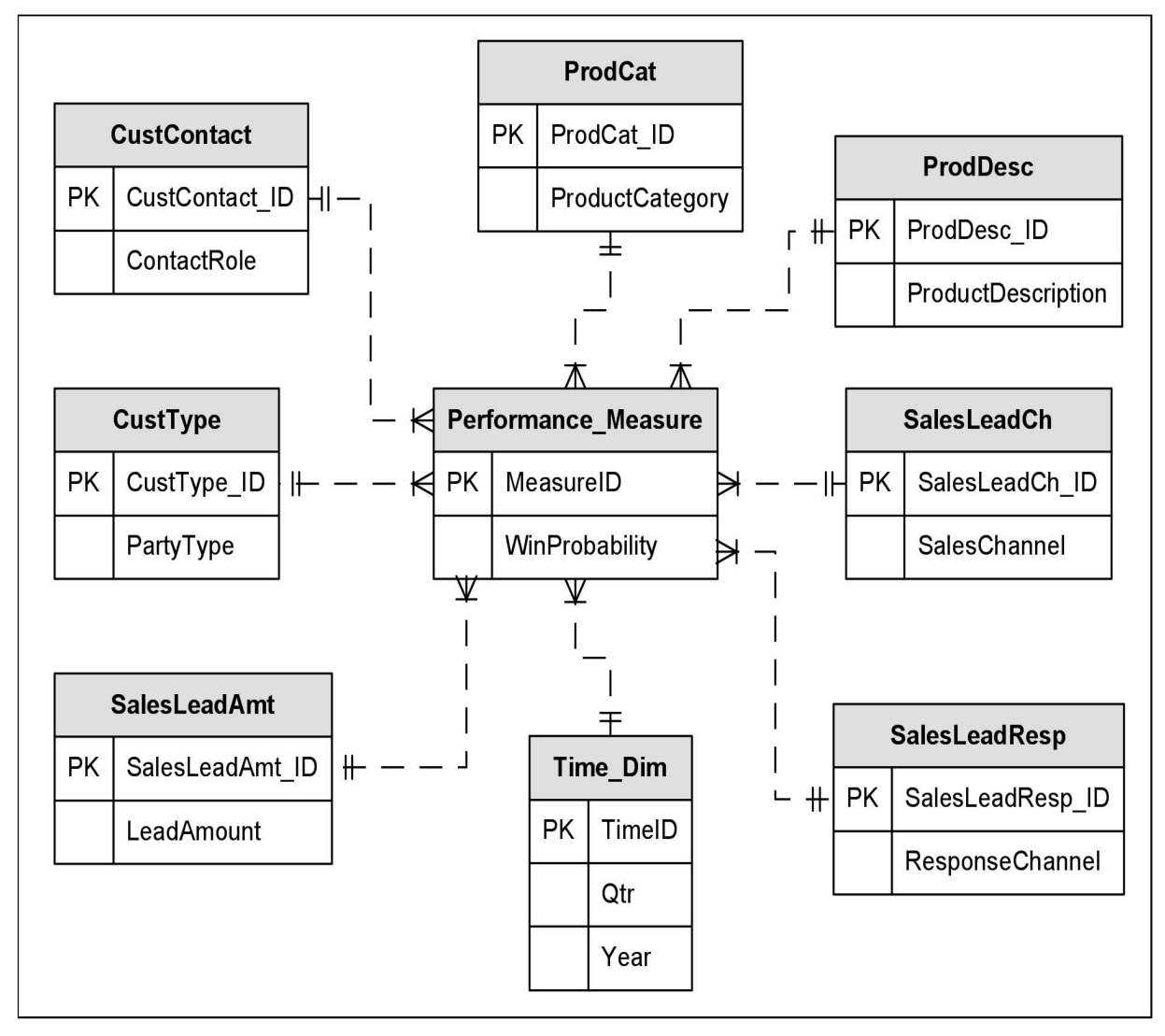

Figure 7. Affinity Cluster Star Schema

A sample of the table structure of the above dimensions and success (fact) measures are listed the Appendix.

\subsection{Develop Affinity Clusters Through Web Prototype}

Star schema analytics for affinity clusters discovers various levels of affinity among dimension attributes for different Win Probability measure values. The Web prototype is developed through Oracle's PL/SQL Server Pages technology [5, 19]. The implementation is PC based.

In general, affinitiy levels can vary depending on business analytic requirements. A very high level of affinity may deliver a combination of dimension factors that can enable the business to capitalize on such factors at the exclusion of other attributes. On the other hand, the difference between the high and low affinity levels may reveal dimension factors that may be dragging the business performance down. So, in the prototype the focus is on a medium affinity level of $50 \%$ and 60\% among attributes with respect to a Win Probability success measure. The prototype consists of three Web pages. The interaction of the three Web pages is shown in Figure 8. 
International Journal of Database Management Systems (IJDMS ) Vol.10, No.5, October 2018

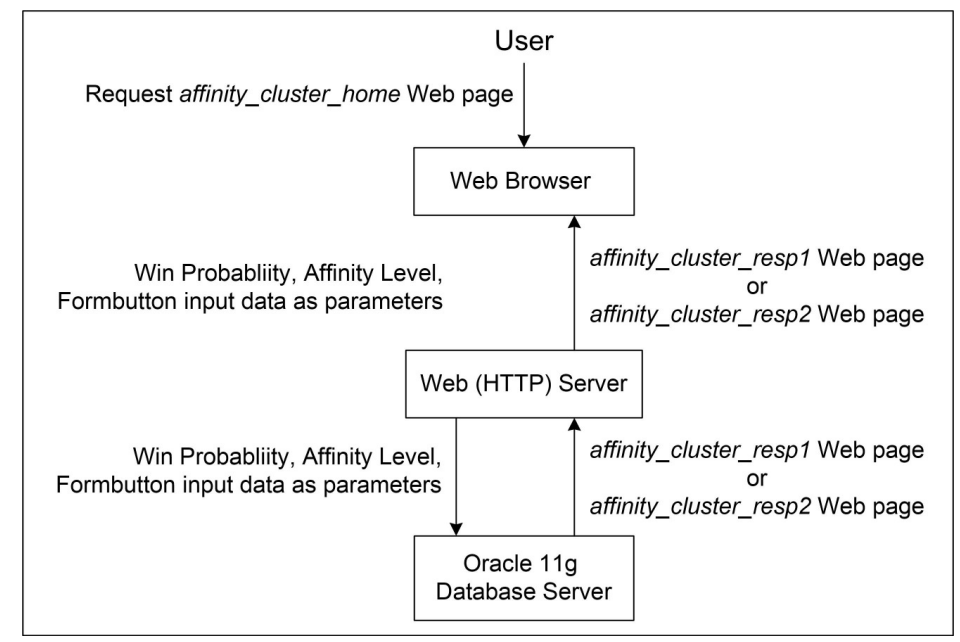

Figure 8. Prototype Web Architecture

The home page (affinity_cluster_home) shown in Figure 9 allows the viewing of affinities in two ways based on user input: (i) individual affinity at $50 \%$ or $60 \%$ level with respect to a Win Probability success measure value, and (ii) show all the affinities that exist for all Win Probability success measure values.

\section{Affinity Clusters for Business Process Intelligence}

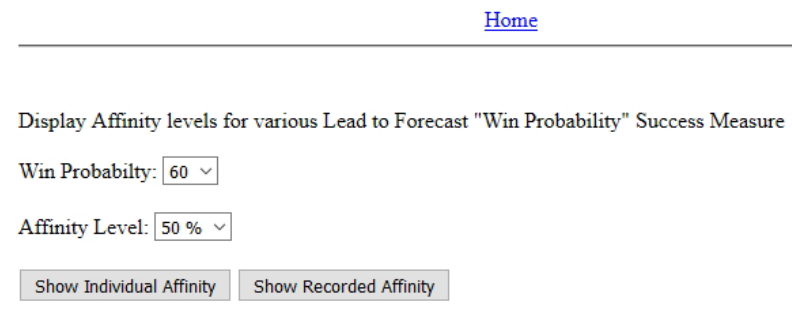

Figure 9. Web Prototype Home Page

Appendix A lists the Web page affinity_cluster_resp1 source that implements the main logic (shown in Figure 10) to generate the individual affinity cluster for specific success measure. Key features of the logic are as follows:

1. SQL queries (part of logic step 1) are developed. For example, the following SQL query lists dimension attributes for a specific Win Probability value (winprob).

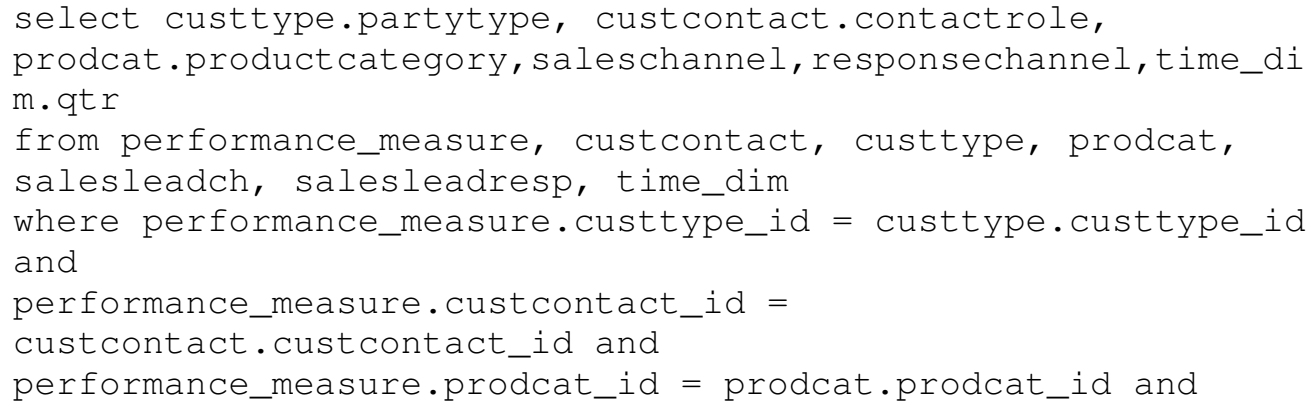


International Journal of Database Management Systems (IJDMS ) Vol.10, No.5, October 2018

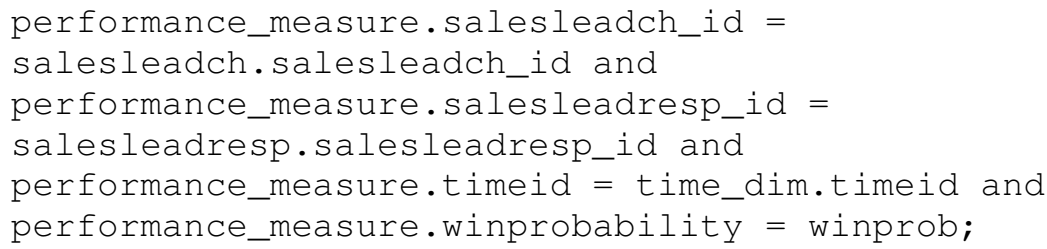

2. Once the query is executed, the procedure counts the instances of each attribute in the query; if the count for an attribute is more or equal to the requested affinity then that attribute becomes part of the cluster that influences the success measure (part of logic steps 2 through 3 ).

3. List each attribute that is part of the of the affinity cluster (part of logic step 4).

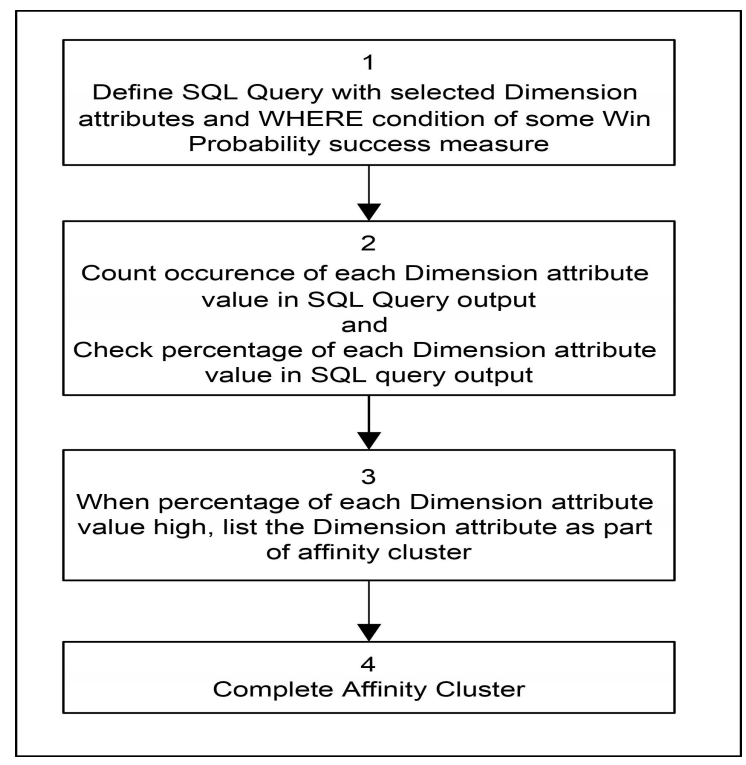

Figure 10. Affinity Cluster Main Logic

The affinity among dimension attributes (factors) that influence Win Probability vary depending on the success measure values. Figure 11 shows the Web page of a specific affinity cluster that impacts Win Probability greater than 50. Figure 12 shows affinities that exist for all Win Probability success measure values.

\section{Affinity Clusters for Business Process Intelligence}

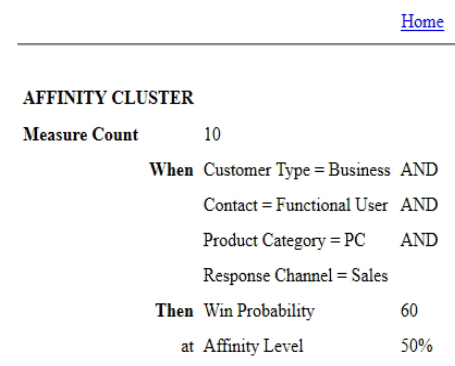

Figure 11. Affinity Cluster for Success Measure 


\section{Affinity Clusters for Business Process Intelligence}

\begin{tabular}{|c|c|c|c|}
\hline \multicolumn{4}{|c|}{ Win Probability Affinities } \\
\hline Measure Count & Measure Value & Affinity $\mathbf{5 0} \%$ & Affinity $60 \%$ \\
\hline 10 & 60 & Customer Type $=$ Business & Product Category $=\mathrm{PC}$ \\
\hline 10 & 60 & Contact $=$ Functional User & Response Channel $=$ Sales \\
\hline 10 & 60 & Product Category $=\mathrm{PC}$ & \\
\hline 10 & 60 & Response Channel $=$ Sales & \\
\hline 7 & 70 & Customer Type $=$ Business & Product Category $=$ Mobile \\
\hline 7 & 70 & Product Category $=$ Mobile & Response Channel $=$ Sales \\
\hline 7 & 70 & Sales Channel $=$ Direct & \\
\hline 7 & 70 & Response Channel $=$ Sales & \\
\hline 4 & 80 & Customer Type $=$ Business & Contact $=$ Functional User \\
\hline 4 & 80 & Contact $=$ Functional User & Product Category $=\mathrm{PC}$ \\
\hline 4 & 80 & Product Category $=\mathrm{PC}$ & \\
\hline 4 & 80 & Sales Channel $=$ Direct & \\
\hline 4 & 80 & Response Channel = Email & \\
\hline 3 & 90 & Contact $=$ Middle Manager User & Contact $=$ Middle Manager User \\
\hline 3 & 90 & Product Category $=\mathrm{PC}$ & Product Category $=\mathrm{PC}$ \\
\hline 3 & 90 & Sales Channel $=$ Exhibition & Sales Channel $=$ Exhibition \\
\hline 3 & 90 & Response Channel $=$ Sales & Response Channel $=$ Sales \\
\hline
\end{tabular}

Figure 12. Affinity Clusters for all success measures

\subsection{Set Analytic Triggers}

Once the analytic clusters are identified, the dimension flow model can assist in identifying the process activity that needs to be monitored with respect to analytic triggers to ensure that the business process performance is maintained or enhanced. For example, suppose the performance goal of the business process is to achieve Win Probability value of 70 . Now, from the list of various affinity clusters listed in Figure 9, Product Category value Mobile and Response Channel value Sales at $60 \%$ affinity have a stronger impact on success measure value 70.

Referencing the dimension flow model in Figure 2, product category dimension attribute is involved in Generate Sales Lead activity and Assess Lead Potential activity. The response channel dimension attribute on the other hand is involved in Generate Sales Lead activity, Assess Lead Potential activity and Convert Lead to Opportunity activity. The analytic trigger now would be to ensure that during these activities emphasis be placed on ensuring that Mobile is the product category and Sales is the response channel.

Another implication of analytic trigger happens if the business process performance needs to be enhanced. Suppose the performance goal of the business process is raised to Win Probability value of 80. Now, from the list of various affinity clusters listed in Figure 9, contact value Functional User and product category value PC at $60 \%$ affinity have a stronger impact on success measure 80. Referencing the dimension flow model in Figure 2, the analytic trigger now should focus on specific activities involving these dimension attributes values to better accomplish enhanced performance targets. 


\subsection{ACCOMPlish Key PerformanCe Metrics}

In continuation of setting analytic triggers, affinity clusters analytics can also lead to the accomplishment of key performance metrics for the business process. Key performance metrics (KPI) are essentially performance metrics that are developed as part of business strategy [30]. Affinity clusters analytics can enable the development of KPI in the form of identifying the dimensional factors that can enable the achievement of business process success goal. For instance, if the KPI for the business process is to achieve Win Probability of 70, then affinity clusters analytics can outline the information in the form of dimensional factors that allows accomplishing such KPI.

\section{Conclusions}

Business process intelligence is all about providing insight and improving efficiency of business processes within an organization. By providing up-to-date insight to the right people at the right time improves the timeliness and quality of decisions needed to remove bottlenecks in any business process. As organizations focus on making smart and intelligent decisions to compete successfully, a key aspects of proper business intelligence deployment is an assessment of whether certain business process measures guarantee success on a continual basis.

This paper provides an approach to outline affinity clusters that ensures continued success of business process. Compared to traditional business process analytics, affinity clusters provide a richer assessment of business process performance. A business can create many affinity clusters for different success measures to gauge optimum avenues for business process success. Utilization of dimension flow model in the paper facilitates the development of multidimensional models that make the business process analysis more responsive to affinity cluster analytics. This results in more dynamic monitoring of business process operations. Further research is ongoing to enhance the approach by embedding more complexity in affinity cluster specification as a way to fine tune business process working.

\section{REFERENCES}

[1] Agrawal, R., Gupta, A. and S. Sarawagi, (1997) "Modeling Multidimensional Databases," Proceedings of the Thirteenth International Conference on Data Engineering, pp. 232-243.

[2] Aalst, W. M. P. van der, Reijers, H. A., Weijters, A. J. M. M., Dongen, B. F. van, Alves, Song, A. K., M de Medeiros and Verbeek, H. M. W. (2007) "Business process mining: An industrial application," Information Systems, Vol. 32, No. 1, pp. 713 - 732.

[3] Aalst, Wil van der (2018) "Spreadsheets for business process management: Using process mining to deal with "events" rather than "numbers"?", Business Process Management Journal, Vol. 24, No. 1, pp.105-127.

[4] Arigliano, F., Ceravolo, P. , Fugazza, C. and Storelli, D. (2008) "Business Metrics Discovery by Business Rules," in M. D. Lytras, J. M. Carroll, E. Damiani (editors), Emerging Technologies and Information Systems for the Knowledge Society: Lecture Notes in Computer Science, Vol. 5288, pp. 395-402.

[5] Boardman, S., Caffrey,M. , Morse, S., and Rosenzweig, B. (2003) Oracle Web Application Programming for PL/SQL Developers, Upper Saddle River, NJ: Prentice-Hall.

[6] Böhnlein M., Ulbrich-vom Ende A. (2000) Business Process Oriented Development of Data Warehouse Structures. In: Jung R., Winter R. (eds) Data Warehousing 2000, Physica, Heidelberg, pp. $3-21$.

[7] Bucher, T., Gericke, A. and Sigg, S. (2009) "Process-centric business intelligence," Business Process Management Journal, Vol. 15, No. 3, pp. 408-429. 
International Journal of Database Management Systems (IJDMS ) Vol.10, No.5, October 2018

[8] Castellanos, M., Casati, F., Sayal, M. and Dayal, U. (2005) "Challenges in business process analysis and optimization," in C. Bussler and M. C. Shan (Eds.), Technologies for E-Services, 6th International Workshop, TES 2005, Trondheim, Norway, September 2-3, 2005, Revised Selected Papers, volume 3811 of Lecture Notes in Computer Science, Springer-Verlag, pp. 1-10.

[9] Castellanos, M., Medeiros, A. Alves de, Mendling, J., Weber, B., and Weijters, A. (2009) "Business Process Intelligence," in J. Cardoso and W. van der Aalst (Eds.) Handbook of Research on Business Process Modeling, IGI: Hershey, PA, pp. 456 - 480 .

[10] Chen, H., Chiang, H. L. Roger and Storey, Veda C. (2012) "Business Intelligence and Analytics: from Big Data to Big Impact” MIS Quarterly, Vol. 36, No. 4, pp. 1165-1188.

[11] Cody, W. F.,Kreulen, J. T., Krishna, V. and Spangler, W. S. (2002) "The integration of business intelligence and knowledge management," IBM Systems Journal, Vol. 41, No. 4, pp. 697-713.

[12]Dayal, U., Wilkinson, K., Simitsis, A. and Castellanos, M. (2009) "Business Processes Meet Operational Business Intelligence," Bulletin of the Technical Committee on Data Engineering, Vol. 32, No. 3, pp. 35-41.

[13]Debevoise, T. (2005) Process Management with a Business Rules Approach: Implementing The Service Oriented Architecture, Business Knowledge Architects, Roanoke.

[14] Dumas, M., Rosa, M. La, Mendling, J. and Reijers, H. A. (2013) "Process intelligence," in Fundamentals of Business Process Management, Springer: Berlin Heidelberg, pp. 353-383.

[15]Elbashira, M. Z., Collierb, P. A. and Davernb, M. J. (2008) "Measuring the effects of business intelligence systems: The relationship between business process and organizational performance," International Journal of Accounting Information Systems, vol. 9, no. 3, pp. 135-153.

[16] Golfarelli, M., Rizzi, S. and Cella, I. (2004) "Beyond data warehousing: what's next in business intelligence?," Proceedings of the 7th ACM international workshop on Data warehousing and OLAP, pp. 1-6.

[17] Grigori, D., Casati, F., Castellanos, M., Dayal, U. , Sayal, M. and Shan, M. (2004) "Business process intelligence," Computers in Industry, Vol. 53, No. 3, pp. 321-343.

[18] Kaula, R. (2012) "Business Intelligence Process Metrics Specification: An Information Flow Approach,” International Journal of Computers and Their Applications, Vol. 19, No. 4, pp. 262-272.

[19] Kaula, R. (2013) Database Design and Application: Developing AJAX Applications with PL/SQL Server Pages, New York, NY: Mc-Graw-Hill.

[20] Kaula, R (2017) "Operational Intelligence through Performance Trends: An Oracle Prototype," International Journal of Business Intelligence and Systems Engineering, Vol. 1, No. 2, pp. 140-165.

[21] Kimball, R. and Ross, M. (2002) The Data Warehouse Toolkit: The Complete Guide to Dimensional Modeling, John Wiley \& Sons, New York.

[22] Kimball, R., Ross, M., Thornthwaite, W., Mundy, J. and Becker, B. (2008) The Data Warehouse Lifecycle Toolkit, John Wiley \& Sons, New York.

[23] Kimball, R. and Ross, M. (2010) The Kimball Group Reader: Relentlessly Practical Tools for Data Warehousing and Business Intelligence, New York: Wiley Publishing.

[24]Loshin, D. (2003) Business Intelligence: The Savvy Manager's Guide, San Francisco: Morgan Kaufman. 
International Journal of Database Management Systems (IJDMS ) Vol.10, No.5, October 2018

[25] Marjanovic, O. (2007) "The Next Stage of Operational Business Intelligence: Creating New Challenges for Business Process Management," Proceedings of the 40th Annual Hawaii International Conference on System Sciences, pp. 215c-215c.

[26] Marjanovic, O. (2010) "Business Value Creation through Business Processes Management and Operational Business Intelligence Integration," 43rd Hawaii International Conference on System Sciences (HICSS), pp. 1-10.

[27] Mircea, M. and Andreescu, A. (2009) "Using Business Rules in Business Intelligence" Journal of Applied Quantitative Methods, vol. 4, no. 3, pp. 382-393.

[28] Olivia, R. (2009) Business Intelligence Success Factors: Tools for Aligning Your Business in the Global Economy, Wiley \& Sons, Hoboken, N.J.

[29] Olszak, C. M. and Ziemba, E. (2007) "Approach to Building and Implementing Business Intelligence Systems," Interdisciplinary Journal of Information, Knowledge, and Management, vol. 2, pp. 135-148.

[30] Parmenter, David (2015) Key Performance Indicators: Developing, Implementing, and Using Winning KPIs, New York: John Wiley \& Sons.

[31] Ponniah, P. (2010) Data Warehousing Fundamentals for IT Professionals (2nd Edition), New York: John Wiley \& Sons.

[32] Schobel J., Reichert M. (2017) Business Process Intelligence Tools. In: Grambow G., Oberhauser R., Reichert M. (eds) Advances in Intelligent Process-Aware Information Systems. Intelligent Systems Reference Library, vol 123. Springer, Cham.

[33] Sharda, R., Dalen, D. and Turban, E. (2013) Business Intelligence: A Managerial Perspective on Analytics, Prentice-Hall, Upper Saddle River.

[34] Sen, A. and Sinha, A. (2005) "A comparison of data warehousing methodologies," Communications of the ACM, vol. 48, no. 3, pp. 79-84.

[35] Sohail, A. and Dominic, P. D. D. (2012) “A gap between Business Process Intelligence and redesign process," Proceedings of the 2012 International Conference on Computer \& Information Science (ICCIS), pp. 136-142.

[36] Tan, W., Shen, J.W., Xu, L., Zhou, B. and Li, L. (2008) “A Business Process Intelligence System for Enterprise Process Performance Management," IEEE Transactions on Systems, Man, and Cybernetics, vol. 38 , no. 6 , pp. $745-756$.

[37] Thom, L.H., Reichert, M., Chiao, C.M., Iochpe, C. and Hess, G.N. (2008) "Inventing Less, Reusing More, and Adding Intelligence to Business Process Modeling," in S.S. Bhowmick, J. Küng, R. Wagner (editors), Database and Expert Systems Applications: Book Series Title: Lecture Notes in Computer Science, vol. 5181, pp. 837-850.

[38] Tilley, Scott and Rosenblatt, Harry J (2017) Systems Analysis And Design, Boston: Cengage Learning.

[39] Watson, H. J. and Wixom, B.H. (2007) "The Current State of Business Intelligence," Computer, vol. 40, no. 9, pp. 96-99.

[40] Wrembel, R. and Koncilia, C. (2007) Data warehouses and OLAP: concepts, architectures, and solutions, Hershey: Idea Group Inc..Lee, S.hyun. \& Kim Mi Na, (2008) "This is my paper", ABC Transactions on ECE, Vol. 10, No. 5, pp120-122. 
International Journal of Database Management Systems (IJDMS ) Vol.10, No.5, October 2018

\section{APPENDIX A}

Table 1. CustContact

\begin{tabular}{|l|l|}
\hline CustConctact_ID & ContactRole \\
\hline 1 & Functional User \\
\hline 2 & Middle Manager \\
\hline 3 & Executive \\
\hline
\end{tabular}

Table 2. CustType

\begin{tabular}{|l|l|}
\hline CustType_ID & PartyType \\
\hline 1 & Business \\
\hline 2 & Person \\
\hline 3 & Charity \\
\hline 4 & Academic \\
\hline
\end{tabular}

Table 3. ProdCat

\begin{tabular}{|l|l|}
\hline Prodcat_ID & ProductCategory \\
\hline 1 & PC \\
\hline 2 & Mobile \\
\hline
\end{tabular}

Table 4. ProdDesc

\begin{tabular}{|l|l|}
\hline ProdDesc_ID & ProductDescription \\
\hline 1 & Sentinel Deluxe Desktop \\
\hline 2 & Apple iPhone6 \\
\hline 3 & Lumia 950 \\
\hline 4 & Cyber Laptop \\
\hline
\end{tabular}

Table 5. SalesleadResp

\begin{tabular}{|l|l|}
\hline SalesLeadResp_ID & ResponseChannel \\
\hline 1 & Sales \\
\hline 2 & Email \\
\hline 3 & User \\
\hline
\end{tabular}

Table 6. SalesleadAmt

\begin{tabular}{|l|l|}
\hline SalesLeadAmt_ID & LeadAmount \\
\hline 1 & 20000 \\
\hline 2 & 25000 \\
\hline 3 & 50000 \\
\hline 4 & 10000 \\
\hline 5 & 15000 \\
\hline
\end{tabular}


International Journal of Database Management Systems (IJDMS ) Vol.10, No.5, October 2018

Table 7. SalesleadCh

\begin{tabular}{|l|l|}
\hline SalesLeadCh_ID & SalesChannel \\
\hline 1 & Direct \\
\hline 2 & Indirect \\
\hline 3 & Phone \\
\hline 4 & Exhibition \\
\hline
\end{tabular}

Table 8. Time_Dim

\begin{tabular}{|c|c|c|}
\hline TimeID & Qtr & Year \\
\hline 1 & 1 & 2013 \\
\hline 2 & 2 & 2013 \\
\hline 3 & 3 & 2013 \\
\hline 4 & 4 & 2013 \\
\hline 5 & 1 & 2014 \\
\hline 6 & 2 & 2014 \\
\hline 7 & 3 & 2014 \\
\hline 8 & 4 & 2014 \\
\hline
\end{tabular}

Table 9. Performance_Measure (Part I)

\begin{tabular}{|l|l|l|l|l|}
\hline \multicolumn{5}{|c|}{ Table 9. Performance_Measure (Part I) } \\
\hline MeasureID & $\begin{array}{l}\text { WinProbabilit } \\
\mathbf{y}\end{array}$ & $\begin{array}{l}\text { SalesLeadAmt_I } \\
\text { D }\end{array}$ & SalesLeadCh_ID & $\begin{array}{l}\text { SalesLeadResp_I } \\
\text { D }\end{array}$ \\
\hline 1 & 80 & 1 & 1 & 1 \\
\hline 2 & 70 & 2 & 2 & 1 \\
\hline 3 & 60 & 3 & 3 & 1 \\
\hline 4 & 60 & 4 & 4 & 2 \\
\hline 5 & 70 & 5 & 1 & 1 \\
\hline 6 & 90 & 2 & 4 & 1 \\
\hline 7 & 60 & 3 & 1 & 1 \\
\hline 8 & 90 & 2 & 1 & 1 \\
\hline
\end{tabular}

\begin{tabular}{|l|l|l|l|l|l|}
\hline \multicolumn{7}{|c|}{ Table 10. Performance_Measure (Part II) } \\
\hline $\begin{array}{l}\text { MeasureI } \\
\text { D }\end{array}$ & $\begin{array}{l}\text { ProdCat_I } \\
\text { D }\end{array}$ & $\begin{array}{l}\text { ProdDesc_I } \\
\text { D }\end{array}$ & $\begin{array}{l}\text { CustContact_I } \\
\text { D }\end{array}$ & $\begin{array}{l}\text { CustType_I } \\
\text { D }\end{array}$ & $\begin{array}{l}\text { TimeI } \\
\text { D }\end{array}$ \\
\hline 1 & 1 & 1 & 1 & 2 & 1 \\
\hline 2 & 2 & 2 & 2 & 2 & 2 \\
\hline 3 & 1 & 1 & 2 & 2 & 3 \\
\hline 4 & 1 & 2 & 1 & 1 & 4 \\
\hline 5 & 2 & 3 & 3 & 1 & 1 \\
\hline 6 & 1 & 4 & 1 & 2 & 2 \\
\hline 7 & 1 & 1 & 1 & 3 & 1 \\
\hline 8 & 1 & 1 & 2 & 4 & 2 \\
\hline
\end{tabular}

